\author{
Marcelo Gama de Abreu \\ F. Javier Belda
}

\section{Neurally adjusted ventilatory assist: letting the respiratory center take over control of ventilation}

Received: 24 April 2013

Accepted: 3 May 2013

Published online: 21 June 2013

(C) Springer-Verlag Berlin Heidelberg and ESICM 2013

M. Gama de Abreu (

Pulmonary Engineering Group, Department of Anesthesiology and Intensive Care Medicine, University Hospital Dresden,

Technische Universität Dresden, Fetscherstr. 74,

01328 Dresden, Germany

e-mail: mgabreu@aol.com

\section{F. J. Belda}

Department of Anesthesiology and Intensive Care Medicine, Hospital Clinico Universitario, University of Valencia,

Valencia, Spain

e-mail: Fco.Javier.Belda@uv.es

In 1999, Sinderby and colleagues [1] described a system based on the use of electrical diaphragmatic activity (Edi) for control of assisted ventilation, which was termed neurally adjusted ventilatory assist (NAVA). In NAVA, a catheter with an array of eight electrode pairs (or nine single electrodes) on its distal end is placed in the esophagus such that the center of the electrode pairs is ideally positioned at the diaphragm level in order to optimally collect the Edi signal (Fig. 1). The signal collected by every second electrodes pair is processed by cross-correlation to determine the position of the diaphragm with respect to the array of electrodes (center signal). Subtraction of signals above and below the diaphragm, which are in opposite phases, yields a new "double-subtracted" electrical signal. Finally, the rootmean-square of both the center and the double-subtracted signals are then combined to the Edi signal, which is converted to inspiratory pressure support using a gain factor (NAVA gain in $\mathrm{cmH}_{2} \mathrm{O} / \mu \mathrm{V}$ ). Since the respiratory center activity changes according to gas exchange and lung stretching, assistance during NAVA is fairly constant within a wide range of NAVA gain values. Obviously, too high and too low NAVA gains may disturb the feedback to the respiratory center.

Despite NAVA being based on neural triggering, pneumatic triggering may prevail if the ventilator detects changes in air flow before triggering by the Edi signal (first-come, first-served principle). In this case, however, an initial inspiratory pressure of $2 \mathrm{cmH}_{2} \mathrm{O}$ is applied and is then guided by the Edi signal. In contrast, if for any reason the Edi signal is deemed by the software to be not adequate, the system may switch to pressure support ventilation (PSV). During expiration, NAVA will cycleoff when the Edi drops to $70 \%$ of its peak value. However, in presence of low Edi levels, this percentage can be lower. Also, cycle-off occurs if the airway pressure exceeds the pressure predicted through the algorithm by 3 $\mathrm{cmH}_{2} \mathrm{O}$. In contrast, during prolonged neural inspiration, cycle-off in infants and adults occurs at 1.5 and $2.5 \mathrm{~s}$, respectively.

The most important advantage of NAVA is improved patient-ventilator synchrony. NAVA has been shown to decrease the occurrence of double triggering and missed efforts [2-4], and to prevent arousal during sleep, as compared to PSV [5]. NAVA has been used successfully under different conditions, including in patients with obstructive [3] as well as restrictive lung disease [6, 7], and during noninvasive ventilation [8]. It is worth noting that the respiratory pattern during NAVA very much resembles the spontaneous breathing pattern, especially in terms of variability of $V_{\mathrm{T}}$ and respiratory frequency [9]. Variable assisted ventilation patterns have been shown to improve lung function and even to decrease ventilatorassociated lung injury in models of acute respiratory distress syndrome $[10,11]$. 
Fig. 1 Schematic

representation of the concept of neurally adjusted ventilation assist (NAVA). The respiratory center excites the diaphragm, which contracts to generate transpulmonary pressure in the lungs. The electrical diaphragmatic signal (Edi) is captured by eight electrode pairs (1-8) mounted on an esophageal catheter, which are amplified, processed and converted into positive airway pressure by a mechanical ventilator

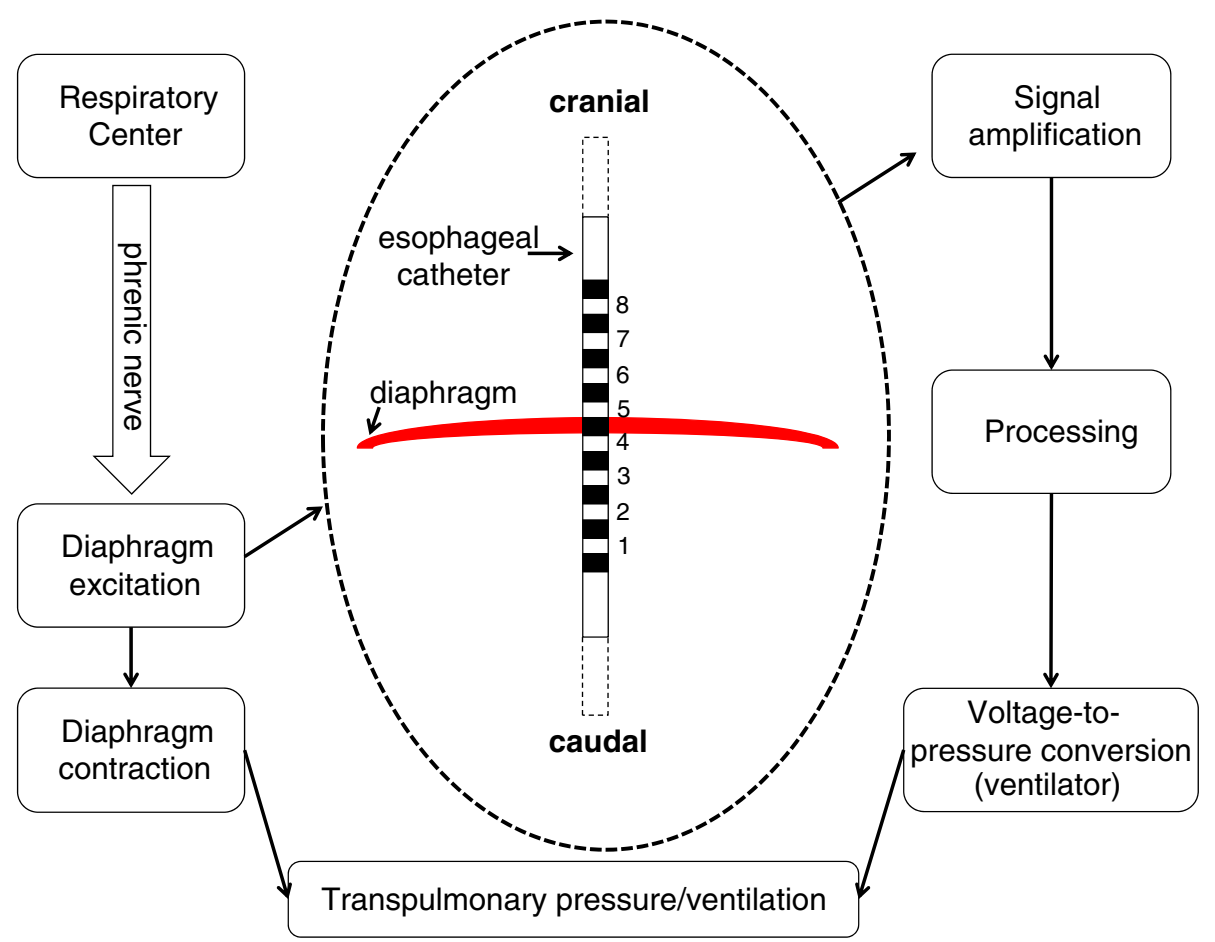

Since during NAVA $V_{\mathrm{T}}$ is modulated in proportion to neural inspiratory drive, some intensive care givers fear that this mode may not be appropriate for protective ventilation. However, experimental data have shown that during NAVA, the average $V_{\mathrm{T}}$ is even lower than $6 \mathrm{~mL} / \mathrm{kg}$, suggesting that during acute lung injury, an intact respiratory center will select $V_{\mathrm{T}}$ values that are rather ultraprotective, i.e. $<4 \mathrm{~mL} / \mathrm{kg}$ [12]. In patients, NAVA induces a stable $V_{\mathrm{T}}$, which only rarely exceeds $8-10 \mathrm{~mL} / \mathrm{kg}[6,13]$. The likely reason is that stretching sensors in the lungs give a feedback signal to the respiratory center, which will limit distension.

In a recent issue of Intensive Care Medicine, Blankman and colleagues [14] reported on the results of a clinical trial on the ability of NAVA to shift lung ventilation towards dependent lung zones, which is likely related to its potential for recruiting lungs. Patients with acute respiratory failure during the weaning phase of mechanical ventilation were ventilated with varying levels of assist from PSV and NAVA. Higher aeration of the dependent lung regions was detected by means of electrical impedance tomography. These results not only support the notion that NAVA yields improved matching between ventilation and perfusion, a phenomenon that has also been observed during other modes of partial ventilatory support [15-17], but may also explain the better arterial oxygenation found during NAVA than during PSV in a previous study [18].

The study by Blankman and colleagues [14] must be interpreted in light of the fact that the positive end-expiratory pressure (PEEP) was kept constant at 10 $\mathrm{cmH}_{2} \mathrm{O}$ in all patients. Recruitment and PEEP influence lung volume, respiratory muscle load and dead space, affecting central respiratory control and respiratory drive, which may influence the NAVA gain. In fact, Passath and colleagues have demonstrated that the NAVA level changes at different PEEP settings [19]. Thus, extrapolation of the settings used in the work by Blankman and colleagues [14] to other situations is not appropriate.

Despite its advantages, NAVA also has important limitations. First, the need for insertion of an esophageal catheter precludes its use in patients with contraindications for a feeding tube. Second, changes in patient position, whether active or passive, may displace the esophageal catheter from its optimal position, with deterioration of the Edi signal. Third, the neural drive originating in the respiratory center may be affected by disease and sedation, leading to respiratory patterns with too low or too high variability, or even average $V_{\mathrm{T}}$ incompatible with lung protection. Fourth, high NAVA gains may cause an irregular respiratory pattern. Fifth, studies on clinically relevant outcome variables and NAVA are still missing.

Taking the present body of evidence and our experience into account, we believe that NAVA may be useful in patients who are facing difficulties in synchronizing with the ventilator despite optimal sedation, particularly those with expiratory flow limitation and changing ventilatory demand, as well as those on noninvasive ventilation with intermittent pressure support. Whatever 
the future teaches us about the use of NAVA, this mode of assisted ventilation has certainly already gained a place among the tools intensive care givers can count on to improve patient care.
Conflicts of interest Marcelo Gama de Abreu was granted patents on variable pressure support ventilation, which have been licensed to Dräger Medical AG (Lübeck, Germany).

\section{References}

1. Sinderby C, Navalesi P, Beck J, Skrobik Y, Comtois N, Friberg S, Gottfried SB, Lindstrom L (1999) Neural control of mechanical ventilation in respiratory failure. Nat Med 5:1433-1436

2. Beck J, Campoccia F, Allo JC, Brander L, Brunet F, Slutsky AS, Sinderby C (2007) Improved synchrony and respiratory unloading by neurally adjusted ventilatory assist (NAVA) in lung-injured rabbits. Pediatr Res 61:289-294

3. Spahija J, de Marchie M, Albert M, Bellemare P, Delisle S, Beck J, Sinderby C (2010) Patient-ventilator interaction during pressure support ventilation and neurally adjusted ventilatory assist. Crit Care Med 38:518-526

4. Moerer O, Beck J, Brander L, Costa R, Quintel M, Slutsky AS, Brunet F, Sinderby C (2008) Subject-ventilator synchrony during neural versus pneumatically triggered non-invasive helmet ventilation. Intensive Care Med 34:1615-1623

5. Delisle S, Ouellet P, Bellemare P, Tetrault JP, Arsenault P (2011) Sleep quality in mechanically ventilated patients: comparison between NAVA and PSV modes. Ann Intensive Care $1: 42$

6. Colombo D, Cammarota G,

Bergamaschi V, De Lucia M, Corte FD, Navalesi P (2008) Physiologic response to varying levels of pressure support and neurally adjusted ventilatory assist in patients with acute respiratory failure. Intensive Care Med 34:2010-2018

7. Terzi N, Pelieu I, Guittet L, Ramakers M, Seguin A, Daubin C, Charbonneau P, du Cheyron D, Lofaso F (2010) Neurally adjusted ventilatory assist in patients recovering spontaneous breathing after acute respiratory distress syndrome: physiological evaluation. Crit Care Med 38:1830-1837

8. Piquilloud L, Tassaux D, Bialais E, Lambermont B, Sottiaux T, Roeseler J, Laterre PF, Jolliet P, Revelly JP (2012) Neurally adjusted ventilatory assist (NAVA) improves patient-ventilator interaction during non-invasive ventilation delivered by face mask. Intensive Care Med 38:1624-1631
9. Schmidt M, Demoule A, Cracco C, Gharbi A, Fiamma MN, Straus C, Duguet A, Gottfried SB, Similowski T (2010) Neurally adjusted ventilatory assist increases respiratory variability and complexity in acute respiratory failure. Anesthesiology 112:670-681

10. Gama de Abreu M, Spieth P, Pelosi P, Carvalho AR, Walter C, SchreiberFerstl A, Aikele P, Neykova B, HÅbler M, Koch T (2008) Noisy pressure support ventilation: a pilot study on a new assisted ventilation mode in experimental lung injury. Crit Care Med 36:818-827

11. Spieth PM, Carvalho AR, Güldner A, Pelosi P, Kirichuk O, Koch T, de Abreu MG (2009) Effects of different levels of pressure support variability in experimental lung injury. Anesthesiology 110(2):342-350

12. Brander L, Sinderby C, Lecomte F, Leong-Poi H, Bell D, Beck J, Tsoporis JN, Vaschetto R, Schultz MJ, Parker TG, Villar J, Zhang H, Slutsky AS (2009) Neurally adjusted ventilatory assist decreases ventilator-induced lung injury and non-pulmonary organ dysfunction in rabbits with acute lung injury. Intensive Care Med 35:1979-1989

13. Patroniti N, Bellani G, Saccavino E, Zanella A, Grasselli G, Isgro S, Milan M, Foti G, Pesenti A (2012) Respiratory pattern during neurally adjusted ventilatory assist in acute respiratory failure patients. Intensive Care Med 38:230-239

14. Blankman P, Hasan D, van Mourik MS, Gommers D (2013) Ventilation distribution measured with EIT at varying levels of pressure support and Neurally Adjusted Ventilatory Assist in patients with ALI. Intensive Care Med 39:1057-1062

15. Wrigge $H$, Zinserling J, Neumann $P$, Muders T, Magnusson A, Putensen C, Hedenstierna G (2005) Spontaneous breathing with airway pressure release ventilation favors ventilation in dependent lung regions and counters cyclic alveolar collapse in oleic-acidinduced lung injury: a randomized controlled computed tomography trial. Crit Care 9:R780-R789
16. Neumann $P$, Wrigge $H$, Zinserling $J$, Hinz J, Maripuu E, Andersson LG, Putensen C, Hedenstierna G (2005) Spontaneous breathing affects the spatial ventilation and perfusion distribution during mechanical ventilatory support. Crit Care Med 33:1090-1095

17. Gama de Abreu M, Cuevas M, Spieth PM, Carvalho AR, Hietschold V, Stroszczynski C, Wiedemann B, Koch T, Pelosi P, Koch E (2010) Regional lung aeration and ventilation during pressure support and biphasic positive airway pressure ventilation in experimental lung injury. Crit Care 14:R34

18. Coisel Y, Chanques G, Jung B, Constantin JM, Capdevila X, Matecki S, Grasso S, Jaber S (2010) Neurally adjusted ventilatory assist in critically ill postoperative patients: a crossover randomized study. Anesthesiology 113(4):925-935

19. Passath C, Takala J, Tuchscherer D, Jakob SM, Sinderby C, Brander L (2010) Physiologic response to changing positive end-expiratory pressure during neurally adjusted ventilatory assist in sedated, critically ill adults. Chest 138:578-587 